Editorial

\title{
Systems Biology in Neuroscience: the Paramount Importance of Data Sharing and Citation
}

\author{
Xavier Gallart-Palau 1,2 \\ 1 Institut Investigació Sanitària Pere Virgili (IISPV), University Hospital Institut Pere Mata (IPM), Reus, \\ E-43204 Tarragona, Spain; xavier.gallart@iispv.cat; Tel. +34-977-759-394 \\ 2 Centro de investigación Biomédica en Salud Mental CIBERSAM, Instituto de Salud Carlos III, \\ 28029 Madrid, Spain
}

Received: 18 September 2020; Accepted: 27 October 2020; Published: 9 November 2020

\section{Editorial Letter to the NeuroOmics Community}

The emergence and maturation, in the last decade, of high powerful technologies in the fields of neurogenomics, neurometabolomics, and neuroproteomics has opened exciting novel possibilities of research [1-4]. These technologies allow exploring the molecular composition of brain and nervous system constituents in a wide and unbiased manner by generating large and complex sets of data that become open to further analysis and interpretation by the research community. In that sense, I strongly believe that every generated set of omics data should become a valuable and solid brick in the global wall of neuroscientific knowledge. These bricks should stand findable and steadily open to further systemic and contextualized interpretations. Thus, it is of paramount importance to store and share the data generated through multi-omics technologies in open and public repositories. Similarly, authors are encouraged to complement or base their original research on shared data available in public repositories when these data can successfully contribute to explore novel hypotheses of the research. Finally, the authors that publish Original Research articles in NeuroSci are highly encouraged to publish data descriptors of their omics generated data in specialized journals; this fact will make their shared data findable and citable increasing at the same time the readership interest of the published interpretations.

\section{References}

1. Hosp, F.; Mann, M. A Primer on Concepts and Applications of Proteomics in Neuroscience. Neuron 2017, 96, 558-571. [CrossRef] [PubMed]

2. Mitchell, K.J. Neurogenomics-towards a more rigorous science. Eur. J. Neurosci. 2018, 47, 109-114. [CrossRef] [PubMed]

3. Natividad, L.A.; Buczynski, M.W.; McClatchy, D.B.; Yates III, J.R. From Synapse to Function: A Perspective on the Role of Neuroproteomics in Elucidating Mechanisms of Drug Addiction. Proteomes 2018, 6, 50. [CrossRef] [PubMed]

4. Qi, M.; Philip, M.C. Single Cell Neurometabolomics. ACS Chem. Neurosci. 2018, 9, 40-50. [CrossRef] [PubMed]

Publisher's Note: MDPI stays neutral with regard to jurisdictional claims in published maps and institutional affiliations.

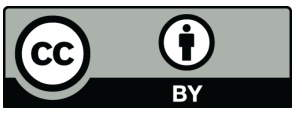

(C) 2020 by the author. Licensee MDPI, Basel, Switzerland. This article is an open access article distributed under the terms and conditions of the Creative Commons Attribution (CC BY) license (http://creativecommons.org/licenses/by/4.0/). 